\title{
Sobre o conceito de redes sociais e seus pesquisadores
}

Sônia Cristina Vermelho'

Ana Paula Machado Velho"

Valdecir Bertoncello"

\section{Resumo}

Este artigo é resultado de pesquisa realizada entre os anos de 2011 e 2013, cujo tema foi redes sociais. 0 problema de pesquisa era identificar o perfil da produção bibliográfica brasileira sobre o referido tema e possibilidades para uso desse espaço na promoção da saúde. Por se tratar de pesquisa de cunho exploratório e descritivo, não foram estabelecidas hipóteses iniciais. 0 estudo teórico permitiu identificar relações históricas do conceito com as ciências naturais e também com estudos da antropologia e da filosofia; porém, evidenciou uma contradição em relação ao conceito de rede social e à experiência individual e coletiva na sociedade atual. Numa segunda etapa, identificaramse os grupos de pesquisa no Brasil que investigam temáticas relacionadas com as redes sociais. Sinteticamente, o resultado em relação a tais grupos mostrou que as áreas de conhecimento predominantes foram a comunicação (39,7\%) e educação (33,3\%). Quanto à região, houve predominâncias de grupos instalados no sudeste $(44,2 \%)$ e, em termos de instituição, uma predominância da Pontifícia Universidade Católica de São Paulo $(17,4 \%)$ e da Universidade de São Paulo (13,9\%). Dos temas descritos em cada um dos grupos, as categorias analíticas "Questões econômicas e sociais" (9,7\%) e "Transformações sociais e culturais" (9\%) apresentaram significância em relação às demais, mostrando um perfil das pesquisas brasileiras com forte componente social.

\section{Palavras-chave}

Rede social digital - Grupos de pesquisa - Pesquisa bibliográfica - Internet.

I-Universidade Federal do Rio de Janeiro, Rio de Janeiro, RJ, Brasil. Contato: cristina.vermelho@gmail.com. II- Centro Universitário de Maringá (UniCesumar), Maringá, PR, Brasil. Contatos: anapaula.mac@gmail.com; valdecir.bertoncello@gmail.com 


\title{
On the concept of social networks and their researchers
}

Sônia Cristina Vermelho'

Ana Paula Machado Velho"

Valdecir Bertoncello"

\begin{abstract}
This article is the result of a study on social networks conducted from 2011 to 2013. The problem in that study was to identify the profile of the Brazilian bibliographic production on the subject and the possibilities of using it to promote health. Because it was an exploratory-descriptive study, no initial hypotheses were established. The theoretical study allowed identifying historical relations between the concept and natural sciences, and with anthropology, and philosophy; however, it revealed a contradiction regarding the concept of social network and the individual and collective experience in current society. In a second phase, we identified research groups in Brazil which investigate subjects related with social networks. In short, we found regarding such groups showed that the dominant knowledge areas were communication (39.7\%) and education (33.3\%). As to the region, groups based in southeast Brazil predominate (44.2\%), and, in terms of institution, Pontifícia Universidade Católica de São Paulo (17.4\%) and Universidade de São Paulo (13.9\%) predominate. Among the themes described in each group, the analysis categories "Social and economic questions" (9.7\%) and "Social and cultural transformations" (9\%) presented significance in relation with the other categories, thus showing that Brazilian research has a strong social component.
\end{abstract}

\section{Keywords}

Digital social network - Research groups - Bibliographic research - Internet.

I-Universidade Federal do Rio de Janeiro, Rio de Janeiro, RJ, Brasil.

Contact: cristina.vermelho@gmail.com

II- Centro Universitário de Maringá

(UniCesumar), Maringá, PR, Brazil.

Contact:anapaula.mac@gmail.com;

valdecir.bertoncello@gmail.com 


\section{Introdução}

$\mathrm{Na}$ história humana, de tempos em tempos, alguns temas emergem a partir de contextos que traduzem o sentido e o espírito da época. Pode-se dizer, com relativa segurança, que um tema emergente da atualidade é o das redes sociais. $\mathrm{Na}$ história das ciências sociais e humanas, o conceito de rede social surgiu na primeira metade do século XX. Contudo, naquele momento,

[...] o termo era sobretudo usado em sentido metafórico: os autores não identificavam características morfológicas, úteis para a descrição de situações específicas, nem estabeleciam relações entre as redes e o comportamento dos indivíduos que as constituem. (PORTUGAL, 2007, p. 4).

Somente a partir da segunda metade do século XX, o conceito assumiu grandes proporções na sociologia. A construção desse conceito se desenvolveu em torno de duas correntes marcadamente distintas: uma no campo da antropologia social, a partir de pesquisadores britânicos após a II Guerra Mundial, e outra, de origem americana, que se preocupou fundamentalmente com uma análise quantitativa a partir de uma abordagem estruturalista (PORTUGAL, 2007).

Sinteticamente, pode-se indicar que, na vertente britânica, os antropólogos começaram a perceber as limitações do modelo teórico estrutural-funcionalista clássico, uma vez que esse se preocupava fundamentalmente com a normatividade dos sistemas culturais. Com esse modelo, os antropólogos não conseguiam explicar certos fenômenos percebidos na sociedade. Segundo Portugal (2007), até aquele momento, o conceito de rede social era utilizado pelos pesquisadores no sentido metafórico e não como conceito explicativo de sistemas sociais; portanto, era limitado às descrições de grupos restritos. Quando os pesquisadores se deparavam com contextos mais complexos, encontravam dificuldades em utilizá-lo. Em função disso, ainda na primeira metade do século $\mathrm{XX}$, a antropologia britânica mudou o foco dos sistemas culturais para os sistemas de redes de relações sociais, chegando, em decorrência, à formulação do conceito de rede social. Após esse período, passou-se a utilizá-lo de maneira sistemática (PORTUGAL, 2007).

Numa outra vertente investigativa, os estudos dos estadunidenses se voltaram mais para a forma dos sistemas sociais, o que os levou a desenvolver métodos quantitativos para descrever o modelo de relações que os grupos estabeleciam. De acordo com Wellman (apud PORTUGAL, 2007, p. 5-6):

Da análise sociométrica, utilizada pelos psicólogos, e pioneira na quantificação de dados relacionais, à teoria dos grafos dos matemáticos, os estudiosos das redes recolheram vocabulário e modos de representação gráfica, inicialmente rudimentares, e, hoje, cada vez mais elaborados, que lhes permitiram analisar quantitativamente "as estruturas profundas que unem e separam os sistemas sociais".

Existe atualmente todo um debate sobre se a teoria das redes na sociologia e antropologia poderia ser encarada como um novo paradigma - no sentido adotado por Kuhn - ou se se trata de uma nova corrente que pretende ser mais adequada para explicar os fenômenos sociais coletivos e individuais. Deve-se, assim, concordar com Portugal que o que parece a maior contribuição da teoria das redes sociais para o entendimento da sociedade é que ela articula os níveis macroestrutural e microestrutural, ou seja:

[...] busca explicar o comportamento dos indivíduos através das redes em que eles se inserem e explicar a estruturação das redes a partir da análise das interacções entre os indivíduos e das suas motivações. (PORTUGAL, 2007, p. 10) 
Para além desse contexto histórico, é necessário refletir a respeito de um momento anterior à formulação dessa concepção, buscando referências em algumas áreas do conhecimento para identificar a própria gênese do conceito. 0 resultado desse processo será discutido a seguir.

\section{Gênese do conceito de rede}

Cada um de nós é uma espécie de encruzilhada onde acontecem coisas. (LÉVI-STRAUSS, 1987, p. 10)

Essa ideia que Lévi Strauss discute no texto "Mito e Significado" remete à imagem de um ponto atravessado por linhas, pois a encruzilhada representada e corporificada pelo/no indivíduo indica que ele passa a ser o entroncamento de vias (possibilidades) por onde circulam coisas (escolhas).

\section{Imagem 1- Imagem simbólica das encruzilhadas da vida}

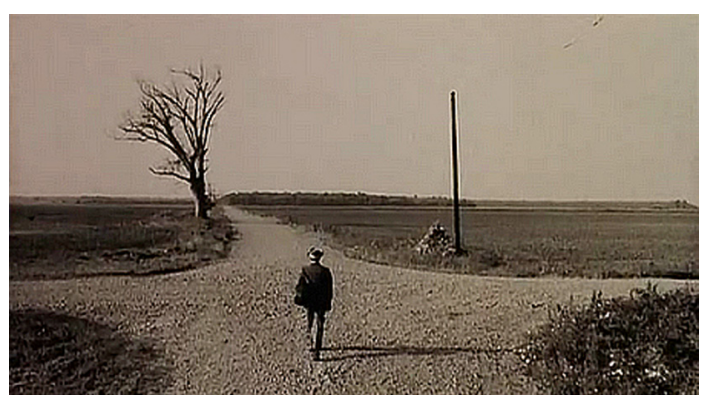

Fonte: <http://maniacosporfilme.wordpress.com/2012/01/08/a-encruzilhadao-mais-maravilhoso-tributo-ao-blues-feito-ate-hoje/>.

A partir da ideia de Lévi-Strauss, e articulando-a com o conceito de rede, pode-se analisar a imagem 1 metaforicamente, como indicadora de dois elementos gráficos primários - o ponto (o indivíduo) e a linha (os caminhos) -, os quais são os elementos fundantes das redes.

1- Imagem do filme Encruzilhada, no qual se discute a condição de escolha que é colocada ao indivíduo na modernidade, e que sugere a dimensão mítico-psicológica desse contexto.
Do ponto de vista da geometria, toda rede é formada por pontos e linhas. Toda linha é formada por uma sequência de pontos, todo ponto é representado no espaço por um par de coordenadas (x,y), o espaço é constituído por planos, os quais são formados por uma secessão de linhas adjacentes e assim por diante.

0 ponto, a linha e o plano foram denominados entes matemáticos pelos gregos, os quais com eles acabaram por construir geometria. A geometria euclidiana, formulada por volta do ano 300 a.C., definiu que por um único ponto passam infinitas retas, que numa reta, bem como fora dela, há infinitos pontos, mas que dois pontos distintos determinam uma única reta. Em um plano e também fora dele, há infinitos pontos. Foi essa geometria que permitiu à ciência medir, dimensionar, projetar, construir e interpretar o espaço físico até o século XIX. Por meio dessa geometria, surgiram as figuras geométricas, as quais organizam a percepção do real.

0 conceito de rede - pontos unidos por linhas -, portanto, traz na sua essência elementos primitivos da ciência que permitiu construir e consolidar as habilidades de perceber o real e atribui-lhe significado. Com isso, pôde-se tecer a primeira consideração acerca da gênese do conceito: o que hoje as áreas do conhecimento reconhecem sob a denominação de rede social é uma construção linguística e cultural, apoiada sobre práticas observacionais que foram se constituindo ao longo da história humana. Essas práticas tiveram um avanço significativo no Renascimento, a partir da geometrização do real e da possibilidade de geração de conhecimento em torno da relação espacial construída pela razão. É, em função disso, um conceito baseado na crença e no pensamento matemático.

A segunda aproximação dessa pesquisa com o conceito foi por meio dos manuais da língua portuguesa. Segundo os dicionários Michaelis e Aurélio (versões on-line), as definições para o substantivo rede estão vinculadas a três funções ou situações: a) relaciona-se a algo ou alguma coisa que tem função de aprisionar, de limitar a movimentação; b) liga-se à estrutura de comuni- 
cação e de transporte; e c) relaciona-se a situações em que há proteção mediante uma delimitação espacial entre o objeto e o meio externo.

No primeiro caso, as imagens-objetos relacionados com esse sentido são exemplificadas com os objetos rede de pesca, de cabelo, de dormir; há também um sentido figurado, em situações em que uma pessoa pode se envolver numa "rede de intrigas". Na imagem 2, exemplificamos as definições encontradas nos dicionários citados.

Imagem 2 - Sentido do conceito de rede: aprisionar

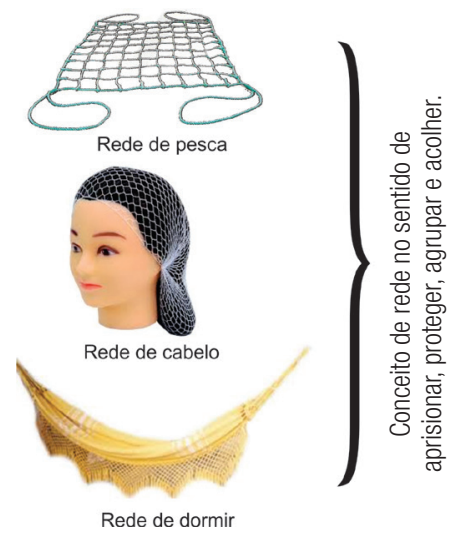

Fonte: Todas as imagens utilizadas na conceituação de rede foram retiradas do banco de imagens do Google e são de domínio público.

Também encontramos nos dicionários outro sentido para o conceito de rede, desta vez relacionado com os sistemas de comunicação; portanto, ao invés de aprisionar, o sentido é o de "possibilitar o movimento de". Na imagem 3, procurou-se demonstrar como esse conceito se materializa na sociedade atual.

0 termo rede, assim, carrega significados ambíguos, visto que indica ao mesmo tempo: aprisionar $\leftarrow \rightarrow$ libertar. Desse modo, existe uma contradição no próprio conceito. Se, por um lado, ele permite colocar em contato entes localizados em locais distintos, uma vez que a rede possibilita estabelecer "relações entre dois pontos", definição que está associada a estrutura de comunicação e transporte, por outro lado, o conceito também permite que seja utilizado em contextos nos quais o que está posto é a limitação de movimentos e, portanto, a não comunicação.
Imagem 3 - Sentido do conceito de rede: comunicar
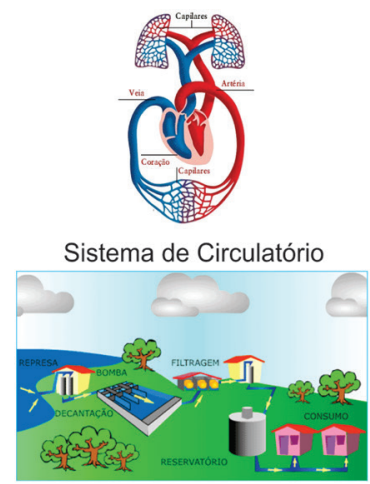

Sistema Urbano de Abastecimento de água

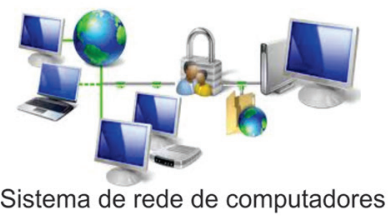

Sistema de rede de computadores

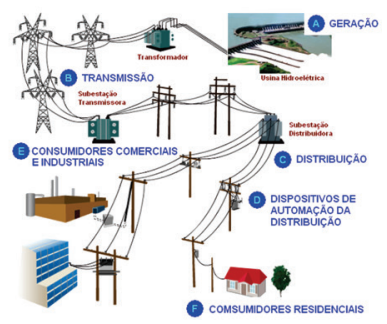

Sistema de Distribuição de Eletricidade

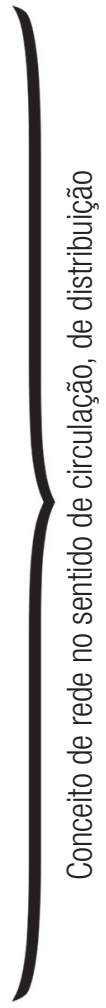

Fonte: banco de imagens do Gloogle.

Diante desse cenário, considera-se pertinente buscar a genealogia do conceito de rede em outras áreas do conhecimento. $\mathrm{Na}$ filosofia, por exemplo, um autor discutiu a gênese do conceito e a relação deste com a ciência. Parrochia (2005) argumentou que a ambiguidade do conceito está associada ao uso mitológico da rede nas situações que envolviam os ritos de guerra entre o gladiador e seu adversário. Diz o autor:

Essa oposição, muito pregnante na Antiguidade, foi então ilustrada pelo confronto simbólico do gladiador (utilizador da espada) e o retiarius (detentor da rede). Os antigos eram tão conscientes das vantagens e desvantagens de ambas as técnicas 
de utilização de armas (mais complementares do que contraditórias) que cada um dos lutadores viu compensar as deficiências de sua principal arma com uma no registo oposto: escudo para o gladiador, o tridente e uma pequena faca para retiarius. (PARROCHIA, 2005, p. 10)

Dos estudos e reflexões acerca dessa relação, pode-se salientar a simbologia criada na Antiguidade em torno do uso das armas e das estratégias de guerra, com as respectivas figuras míticas, as quais se associavam e acabaram por impregnar o conceito de rede. Deve-se considerar também que circulação e comunicação na mitologia grega estavam associadas a várias figuras mitológicas. Talvez Hermes seja a figura mítica mais próxima e representativa do conceito de rede. A complexidade dessa figura mitológica, segundo Brandão (1986), faz com que ele seja associado à função de "Deus mediador entre os mundos”, e também das viagens, dos pastores, dos ladrões. A imagem desse mito também está relacionada com a ideia de artifício, das armadilhas e do labirinto. Os estudos da mitologia podem, por sua vez, trazer elementos para compreender a associação do conceito de rede que aparece hoje nos dicionários da língua à ideia de "rede de intrigas". Esses estudos permitiram entender que o conceito de rede permaneceu, então, preso à materialidade e acabou por se associar ao espaço de forma mais orgânica e ampliada somente no período romano.

A história da civilização romana na Antiguidade indica que os povoamentos tiveram a necessidade de organizar a vida nas cidades por meio da criação de técnicas e estratégias que permitiam organizar a circulação de pessoas e produtos. Os romanos criaram estradas, aquedutos, sistemas de distribuição e drenagem urbana. Contudo, segundo Parrochia “[...] não usavam a palavra rete-retis para designar estes sistemas de distribuição ou comunicação" (PARROCHIA, 2005, p. 13-14).

Ainda que hoje se possa interpretar essas tecnologias como sendo sistemas de redes, o conceito não era utilizado nesse contexto. As pesquisas atuais indicam que o conceito era empregado na Antiguidade predominantemente pelos tecelões, como metáfora para explicar a estrutura dos tecidos fabricados com fibras vegetais e animais, e que permaneceu sem grandes alterações até o século XVII. Contudo, ao longo do século XVIII, passou a inspirar as reflexões sobre as descobertas da anatomia do corpo humano, sobre a natureza e sua configuração.

Pode-se indicar que, no início, ocorreu nos estudos da química (cristalografia), passando pelos estudos das estratégias militares e dispositivos de fortificação, bem como pelas pesquisas acerca das formas geométricas. Nessa trajetória, o conceito “[...] pela primeira vez, de maneira verdadeiramente racional, vai ser utilizado na área geográfica" (PARROCHIA, 2005, p. 12). Para além do espaço, a ideia de rede também inspirou as ciências médicas, a filosofia e a nascente sociologia.

A associação entre rede $\mathrm{e}$ as demais áreas, distintas aos olhos da atualidade, teve grande avanço com as pesquisas a respeito da anatomia do corpo humano, em especial sobre a função do coração no sistema circulatório. No século XVII, descobriu-se que o sistema circulatório funcionava como uma rede de fluxos sanguíneos bombeados pelo coração, que colocava em movimento (circulação) o sangue do corpo. Da explicação do corpo humano para o corpo social, foi uma questão de tempo e de associação de ideias. Segundo Parrochia:

Via medicina e hidráulica, rede adquire o sentido de promover a capacidade circulatória. 0 desenvolvimento de grandes redes de transporte no século XIX (rede rodoviária e ferroviária) irá sustentar essa possibilidade. (PARROCHIA, 2005, p. 15).

Nos séculos seguintes, é encontrada referência na sociologia e na história, as quais permitem associar a rede de transporte à aceleração do crescimento industrial e à nascente economia capitalista (CASTELLS, 
1999). A rede está na essência do sistema econômico capitalista de mercado, que, num primeiro momento, colocou em contato a fonte dos recursos naturais e os centros de produção (indústria) por meio da rede de transporte ferroviário, um sistema de circulação de matéria-prima até os centros produtores. As redes de circulação também colocaram em contato os mercados e as mercadorias, multiplicando em muito o potencial mercadológico do modelo econômico. Como expõe Santos:

[...] as redes buscam mundializar-se, e fisicamente o fazem, mas seu funcionamento é limitado. [...] Quanto mais avança a civilização material, mais se impõe o caráter deliberado na constituição de redes. (1999, p. 211).

Assim sendo, o desenvolvimento de tecnologias de suporte às redes de circulação teve, no século XIX, o seguinte desdobramento:

Multiplicando a velocidade das cargas rebocadas em dez por cento abre-se o caminho para revolucionar a economia: o carvão agora difundindo longe minas, acelerou a produção industrial e o comércio. 0 Turismo vai seguir o exemplo. (PARROCHIA, 2005, p. 15).

Com certa segurança, é possivel inferir que esse processo possibilitou, no século XX, a circulação de mercadorias em proporções mundiais. Se agruparmos a isso as descobertas no campo das telecomunicações, vê-se que, como diz Parrochia (2005):

[...] o planeta é coberto por redes gradualmente invisíveis, que contribuem objetivamente com a construção do pensamento do Homem contemporâneo. (PARROCHIA, 2005, p. 15).

Ou seja, das ciências naturais até a sociedade, a organização em redes foi o que possibilitou a estruturação da sociedade atual.
Por outro lado, do ponto de vista da filosofia, é com Saint Simon, em uma reflexão sobre o ideal de sociedade, que a noção de rede chega à sua formulação mais acabada e inovadora, e atinge seu clímax antes da modernidade:

[...] o corpo humano é um conjunto de redes de canais compostos, embarcações e vários tubos. A saúde do corpo (como o humano social) envolve a liberação de tráfego em redes de circulação do sangue no corpo humano, assim com a circulação de recursos no corpo social. (apud PARROCHIA, 2005, p. 16).

Conclui-se, assim, preliminarmente, que somente na primeira metade do século XX é que foi possível o conceito de rede social nas ciências sociais e humanas, em função desse processo crescente de articulação do conceito com as práticas e situações em níveis macro e microestruturais. Antes disso:

[...] o termo era sobretudo usado em sentido metafórico: os autores não identificavam características morfológicas, úteis para a descrição de situações específicas, nem estabeleciam relações entre as redes e o comportamento dos indivíduos que as constituem. (PORTUGAL, 2007, p. 4).

É importante esclarecer que a abordagem adotada neste estudo não teve a intenção de mapear ou esgotar a discussão teórica contemporânea em torno do conceito de rede social. Temos ciência de que vários pesquisadores de renome internacional e referência teórica em várias áreas, tais como Frijof Kapra, Ilya Prigogine, Humberto Maturana, entre tantos outros, trazem uma contribuição significativa para as discussões envolvendo esse conceito.

Assim, buscou-se, com esses estudos, procurar outras referências em torno da significação de rede social para articulá-los aos demais pesquisadores das ciências naturais, tais como os citados acima. Esses estudos levaram 
os pesquisadores a considerar que o conceito tem, na sua gênese, uma profunda relação com experiências ligadas à pré-história da civilização. Ou seja, tanto a construção teórica dos elementos constituintes das redes (ponto e linha) quanto a utilização desse modelo teórico para a explicação do mundo pode ter sua gênese em experiências anteriores à formação cultural da sociedade.

Esses estudos nos levaram à formulação da hipótese de trabalho de que o conceito de rede tem sua origem na natureza, e não na cultura. Ou seja, a construção do conceito teórico foi possível porque a natureza é constituída numa estrutura de rede. A rede, portanto, constitui-nos biologicamente. Esse aspecto foi central para a formulação do conceito abstrato de rede social. Posteriormente, com a linguagem, pôde ser formulado o conceito para expressar uma forma de organização social.

$\mathrm{Na}$ busca pelas referências conceituais e imagéticas do conceito de rede, encontramos imagens de representação da estrutura de elementos da natureza, os quais passamos a analisar para vislumbrar a similaridade ou não entre o elemento natural e a definição de rede social.

Um dos exemplos que podemos expor diz respeito à busca que realizamos nos materiais didáticos quanto às representações de estruturas da matéria cujo conteúdo é ensinado na educação básica. Dentre as imagens, encontramos aquelas utilizadas na representação da estrutura dos cristais de vidro, que é feito de silício, as formas das redes (retículas), ou seja, relacionamos os fenômenos naturais com a imagem-conceito de rede. Na imagem 4, ilustramos a estrutura molecular do silício, que é formalizada como uma rede.

Também encontramos outra referência interessante associada ao funcionamento dos organismos vivos. Sabemos que todas as proteínas que compõem o nosso organismo são constituídas por sequências de aminoácidos ligados covalentemente. Esses compostos possuem grupos $-\mathrm{OH}$ e - $\mathrm{NH}$, capazes de formar uma forte rede de ligações intermoleculares.
Imagem 4 - Estrutura do silício usado para representar a composição do vidro<smiles>CC(C)C[C@@H](N(C)C)C1(c2ccc(Cl)cc2)CCC1</smiles><smiles>CC(C)C[C@H](N(C)C)C1(c2ccc(Cl)cc2)CCC1</smiles>

Fonte: <http://www.educadores.diaadia.pr.gov.br/modules/mylinks/viewcat. php? cid=16\&letter=S\&min $>, 2012$.

É isso que confere a estrutura terciária das proteínas, isto é, a sua forma característica de orientação espacial. Essa configuração pode ser visualizada também na representação do DNA de todos os humanos: sua forma de dupla-hélice, a qual é mantida graças às ligações de hidrogênio entre os grupos dos - $\mathrm{OH}$ e $-\mathrm{NH}$ das bases nitrogenadas heterocíclicas que o compõem o GCAT. As imagens 5 e 6 nos mostram a representação gráfica desses compostos.

Imagem $\mathbf{5}$ - Estrutura de relações em rede da configuração espacial do DNA
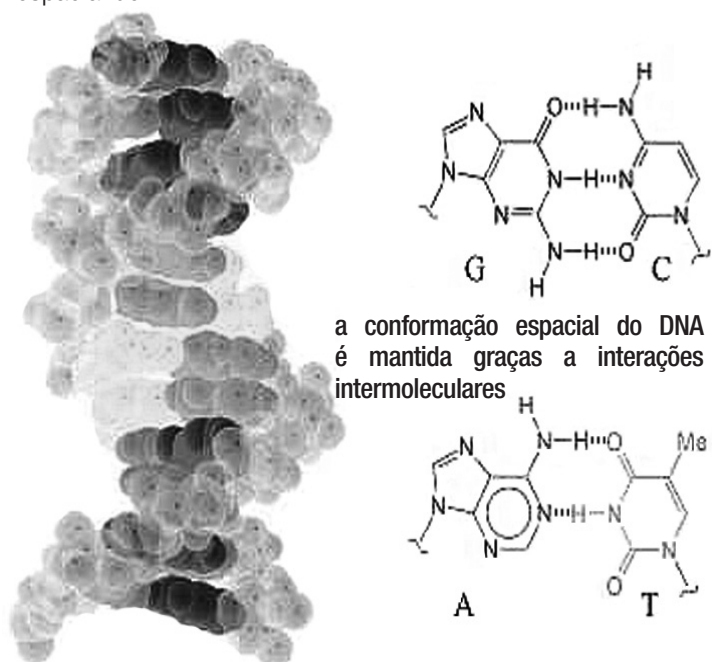

Fonte: <http://www.profpc.com.br/For\%C3\%A7as\%20Intermoleculares/ For\%C3\%A7as_intermoculares.htm>. 
Outra imagem interessante é a 6, em que encontramos uma representação do modo de funcionamento do DNA, o qual opera segundo uma articulação realizada entre os elementos de redes de moléculas.

Imagem 6- Esquema de funcionamento do DNA

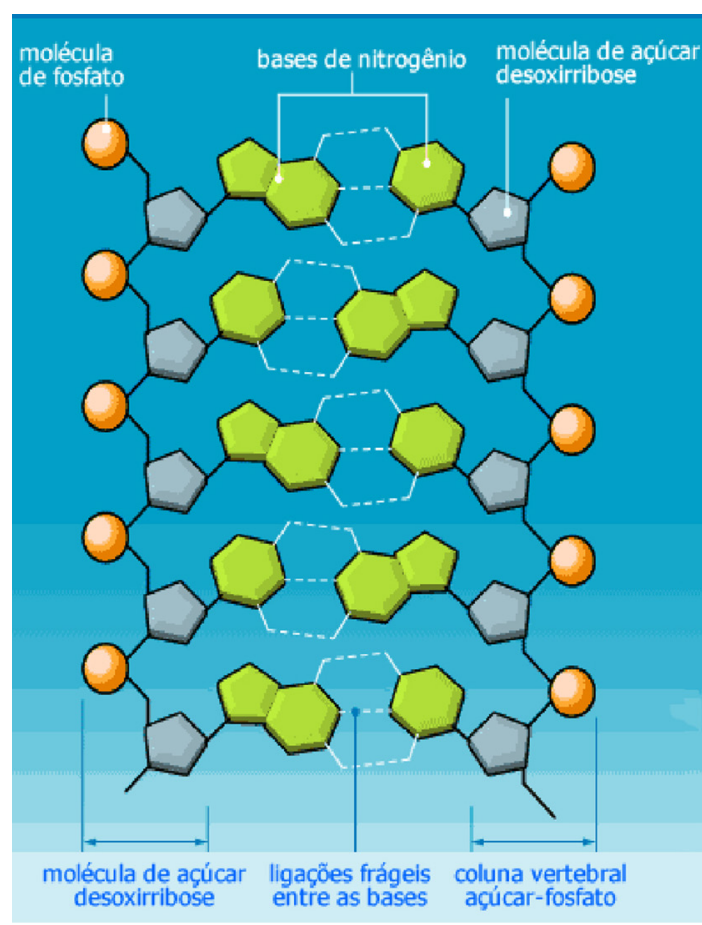

Fonte: <http://saude.hsw.uol.com.br/dna1.htm>, 2012.

A ligação covalente (linha), entretanto, é intramolecular, ou seja, apenas une os átomos que formam a molécula. Em termos químicos, portanto, o que impede que todas as moléculas em um copo de água se difundam instantaneamente pelo meio, deixando o copo vazio? 0 que as mantém unidas? Ou, ainda, o que possibilita que se transformem num objeto sólido, compacto, quando resfriadas? As ciências químicas já nos responderam essa questão, informando-nos que as forças que existem entre as moléculas - forças intermoleculares - não são tão poderosas quanto as ligações iônicas ou covalentes, mas são muito importantes; sobretudo quando se deseja explicar as propriedades macroscópicas da substância, ou seja, como os corpos se mantêm na forma de matéria. São essas forças as responsáveis pela existência dos três estados físicos. Sem elas, só existiriam gases.

Imagem 7 - Representação gráfica dos três estados da matéria

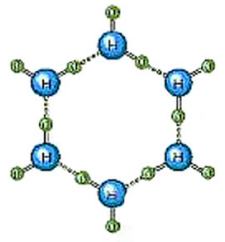

sólido

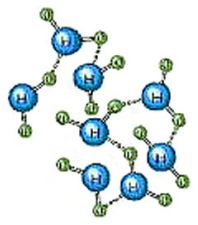

liquido

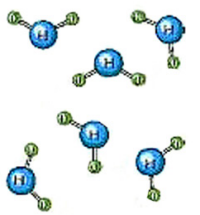

gasoso
Fonte: <http://fisicaetc.hdfree.com.br/ESTADOS\%20DA\%20MATERIA.html>, 2012.

Ou seja, existem forças intramoleculares que ligam as moléculas entre si, tais como as linhas ligam os pontos e criam as estruturas de pontos e linhas, ou seja, possibilitam a formação das redes.

Esses levantamentos imagéticos foram interessantes para analisarmos as representações visuais das redes criadas pelas distintas áreas do conhecimento. E o mais interessante é que essas representações vêm sendo utilizadas como modelos conceituais e matemáticos para os estudos das redes sociais digitais. Tais representações, conforme identificamos, possuem uma grande similaridade com as criações imagéticas das substâncias da natureza. Vejamos, a seguir, as representações mais comumente encontradas, segundo algumas áreas do conhecimento ou disciplinas.

Imagem 8 - Topologias das redes: ciência da informação

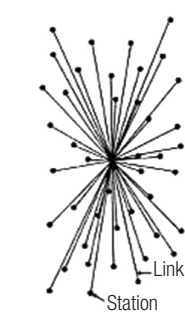

CENTRALIZED

(A)

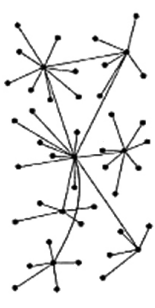

(B)

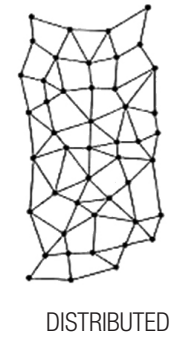

(C)
Fonte: <http://www.rand.org/content/dam/rand/pubs/papers/2005/P2626.pdf>. 
As imagens acima são comumente associadas à conceituação de rede no campo das ciências da informação.

Imagem 9 - Topologias das redes: informática
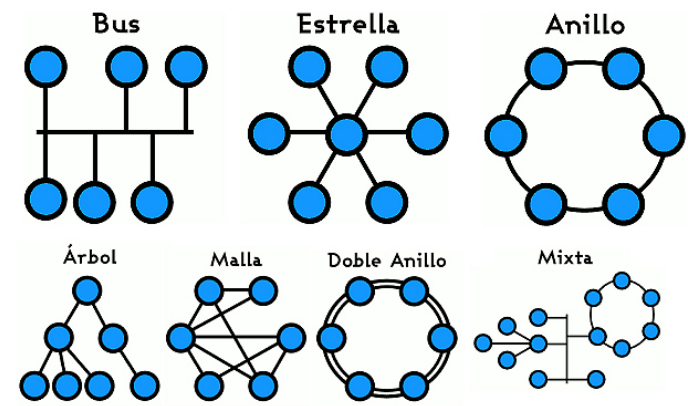

Fonte: <http://www.dalef5.com/>

As imagens utilizadas para representar as redes de computadores apresentaram uma diversidade maior de possibilidades em termos de configuração e de fluxo.

Imagem 10 - Topologias das redes: física

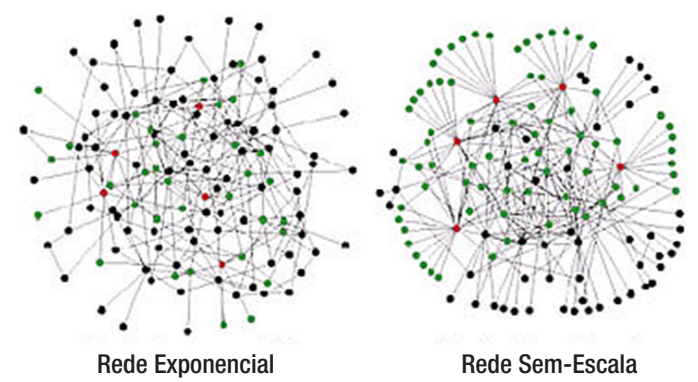

Fonte: CBPF. <http://portal.cbpf.br/index.php?page=tecnologia.cat_comp >.

Em busca do termo rede associado às ciências naturais, em particular à física, encontramos (imagem 10) dois modelos conceituais para exemplificar as redes em termos de topologia.

E, finalmente, na busca pelo termo rede associado aos meios de comunicação, encontramos a representação utilizada na imagem 11, a qual mostra ainda um sistema de comunicação baseado no broadcasting.
Imagem 11 - Topologias das redes: comunicação

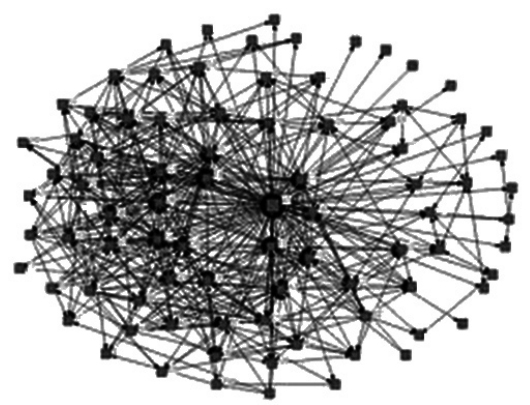

Fonte: <http://www2.cultura.gov.br/site/2009/02/04/broadcast-do-eu-twittere-as-redes-sociais/>., 2012

Dessas representações, procuramos realizar uma comparação entre a simbologia utilizada para representar os estados da matéria e as construções imagéticas culturais, buscando perceber as similaridades entre as estruturas da natureza e a configuração das redes sociais. Vejamos as imagens a seguir:

Imagem 12 - Comparação entre as representações
Imagens da matéria

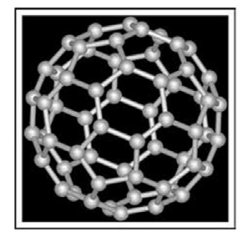

Buckyballs

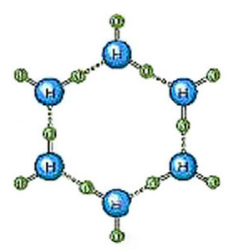

Estado sólido

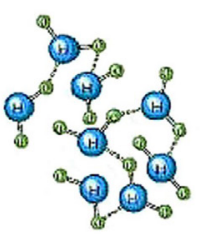

Estado líquido
Imagens da rede social

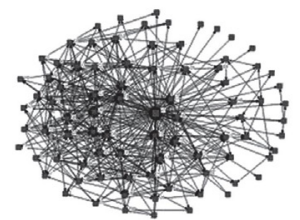

Modelo broadcast sem o núcleo central

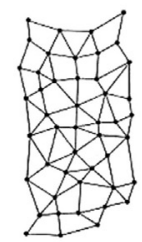

Rede distribuída

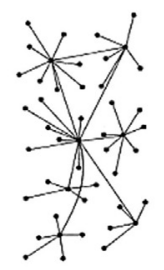

Rede descentralizada
Fonte: elaboração dos autores. 
Nesse esforço por encontrar referências que nos possibilitem entender a complexidade do fenômeno das redes sociais na atualidade, pensamos que as imagens identificadas acima nos abrem possibilidades de reflexão acerca das referidas redes sociais, particularmente as redes sociais digitais.

Por um lado, essas imagens nos alimentaram com suposições, que ainda carecem de investigações mais aprofundadas sobre essa relação entre elementos da natureza e a estruturação das redes sociais. Por outro lado, reforçaram nossa hipótese de que haveria uma contradição subjacente ao conceito de rede social, a qual coloca em confronto o conceito e a experiência relacional humana. A seguir, buscamos explicitar essa contradição.

\section{Contradições do conceito de rede social}

A inquietação em torno do conceito de rede social deveu-se fundamentalmente ao fato de nos debruçarmos sobre as pesquisas que lidaram com o fenômeno das redes sociais para analisar sua potencialidade para a promoção da saúde. Neste momento, porém, buscamos um percurso diferenciado das tradicionais abordagens quantitativas que mapeiam as redes para identificar sua estrutura e a densidade de seus nós e ligações. Importava-nos compreender o fenômeno das redes sociais digitais a partir de sua natureza social e cognitiva; portanto, de modo muito mais vinculado à dimensão social, aos aspectos integrantes dessa prática social.

Como tal, foi necessário entender por que um conceito que foi usado, até determinado momento da história humana, em situações restritas transformou-se num conceito explicativo da sociedade e, mais recentemente, em modelo teórico para direcionar o desenvolvimento de uma tecnologia.

Essa questão foi colocada tendo como pressuposto que vivemos numa sociedade em que todas as instituições - com raras exceções - são organizadas a partir de uma estrutura hierárquica: no trabalho, na família, na escola, no lazer etc. Desde a mitologia grega, história que remete às origens da formação e da construção dos conceitos do pensamento racional, privilegiou-se a ideia de uma organização social com hierarquia. Mesmo com a derrocada do mito e o surgimento de uma religiosidade fundada sobre Deus, passando pelo pensamento científico da modernidade, a estrutura de relações sociais foi idealizada e realizada sobre uma hierarquia. Portanto, podemos pensar que temos uma formação subjetiva quanto à estrutura de relações sociais fundada sobre a ideia de uma hierarquia: entre escravos e senhores, entre pais e filhos, patrão e empregado, Deus e homem, e assim por diante. Ou seja, a base do pensamento racional ocidental tem a estrutura hierárquica como parâmetro para organizar as relações sociais.

Como exceção, encontramos na filosofia clássica a ideia de uma sociedade de iguais, sem hierarquia, idealizada, construída e registrada primeiramente no livro Utopia, de Thomas Morus, em 1503, cuja inspiração foi Platão, em sua obra $A$ República. No seu prefácio, na edição disponível on-line, o editor esclarece:

Thomas Morus, depois de ter na "Utopia" feito uma sátira a todas as instituições da época, edifica uma sociedade imaginária, ideal, sem propriedade privada, com absoluta comunidade de bens e do solo, sem antagonismos entre a cidade e o campo, sem trabalho assalariado, sem gastos supérfluos e luxos excessivos, com o Estado como órgão administrador da produção etc. Embora o caráter essencialmente imaginário e quimérico da "Utopia”, a obra de Morus fica na história do socialismo como a primeira tentativa teórica da edificação de uma sociedade baseada na comunidade dos bens. E o seu nome ficou para sempre incorporado ao vocabulário universal como o significado do [sic] todo sonho generoso de renovação social. (MORUS, 2012, p. 3). 
Sabemos que a idealização de uma sociedade sem hierarquia, enquanto uma utopia, vem acompanhando grupos ou classes sociais que há gerações a alimentam em seu imaginário. No século XIX, a ideia foi estruturante do pensamento de Marx (1985, 2001, 2008) e esteve presente na construção do arcabouço teórico e conceitual da filosofia marxista.

Esse ideal animou vários outros pensadores ao longo dos séculos, que formularam teorias sociais e políticas para a realização de uma sociedade de iguais. Nos séculos XIX e XX, alimentou movimentos sociais e levantes de tomadas de poder, dividindo o mundo em dois grandes blocos até fins do século XX. Porém, ainda que a ideia de uma sociedade de iguais estivesse no cerne das teorias e dos ideários políticos de um dos blocos - o dos socialistas -, na prática, eles atuaram sob um regime hierárquico (MARCUSE, 1968, 1969; ADORNO; HORKHEIMER, 1986). Ou seja, a ideia de uma sociedade sem hierarquia nunca se realizou na história da sociedade ocidental, ainda permanece uma utopia ( $\mathrm{u}=$ não, topos=lugar), um lugar que (ainda) não existe.

Portanto, em primeiro lugar, uma sociedade fundada sobre relações horizontais, sem hierarquia, de iguais, esteve, até os dias atuais, na dimensão da utopia. Não pensamos ser possível afirmar que nossa cultura (ocidental) carregue em sua bagagem experiências alicerçadas em relações horizontais. Desde a socialização no grupo primário (família) até o final da vida, o indivíduo passa por experiências coletivas baseadas em relações sociais hierárquicas. Com isso, consideramos que relações sociais organizadas em torno da horizontalidade estão no campo do imaginário coletivo (JUNG, 2002), mas não se realizaram ainda na história humana.

É importante frisar isso porque, do ponto de vista do desenvolvimento tecnológico, a história humana nos conta que o que impulsionou o desenvolvimento de tecnologias foi, num primeiro momento, a busca por atender necessidades básicas de sobrevivência (lança, roda, fogo etc.) (MARX, 1985), e foi só muito posteriormente que o desenvolvimento tecnológico foi impulsionado por fatores econômicos (MARCUSE, 1969; HARVEY, 1994).

Independentemente disso, toda tecnologia visa a substituir uma ação que antes era realizada pelas mãos ou mente ou a ampliar uma capacidade humana. E a necessidade (subjetiva, objetiva e/ou econômica), portanto, é o que mobiliza o intelecto para a criação de algo novo. A necessidade surge, portanto, da experiência do sujeito com o real, para suprir uma falta ou ampliar uma capacidade: no caso do carro, a de se movimentar; no da calculadora, a de calcular; no da mídia, a de comunicar; a pá-carregadeira substitui os braços e as mãos para transportar etc. Toda tecnologia visa ao humano, para ampliá-lo ou completá-lo.

Nessa linha de raciocínio, tomemos a mídia, que nesta reflexão nos interessa em particular, já que atua na base do estabelecimento de relações sociais na sua forma ampliada, ou seja, com o uso de ferramentas informáticas. Até determinado momento, a experiência humana com a mídia havia se organizado a partir de uma estrutura midiática hierárquica que correspondeu à organização da sociedade, articulada em torno do conceito de broadcasting, com uma produção centralizada emitida para as massas por meio de uma estrutura de comunicação unidirecional em níveis. Ou seja, a estrutura midiática e a organização social mantinham uma relação de similaridade, ambas verticalizadas na sua produção e organização.

Contudo, as redes sociais digitais (RSD), mesmo com todo o seu teor e viés econômico, criadas num momento em que a sociedade está altamente verticalizada, passaram a proporcionar aos seus usuários experiências de relações sociais horizontalizadas. Nossa discussão, portanto, levou-nos a considerar que as experiências com as RSD, do ponto de vista da estrutura das relações, estão na contramão da própria organização social vigente, pois elas proporcionam experiências relacionais distintas daquelas que os sujeitos experimentam na vida 
cotidiana. Ou seja, em geral, nos espaços reais, as relações sociais se organizam a partir de uma hierarquia (chefe-funcionário, pai-filho etc), e nas RSD essa hierarquia não existe.

Pensamos que esse fato possibilita, por princípio, uma contradição em termos de experiência. É uma clivagem do ponto de vista da experiência humana, em termos da relação do sujeito com o coletivo. Pensar o coletivo, até então, em praticamente qualquer dimensão e lugar, era pressupor ter alguém ou algum grupo que assumia uma condição superior aos demais, independentemente de se isso se dava por aspectos econômicos ou culturais. Não nos interessa discutir aqui a natureza dessa superioridade, mas sim a superioridade em si, pois a existência de uma superioridade implica, necessariamente, a existência de uma inferioridade.

Essa linha de raciocínio encontrou algum subsídio nos textos de Manuel Castells. Em relação aos fatores econômicos relacionados à internet, Castells $(1999,2003)$ nos traz uma reflexão interessante. Diz ele:

A elasticidade da Internet a torna particularmente suscetivel a intensificar tendências contraditórias presentes em nosso mundo. Nem utopia nem distopia, a Internet é a expressão de nós mesmos através de um código de comunicação específico, que devemos compreender se quisermos mudar nossa realidade. [...] [A invenção da Internet] reforça também a ideia de que a cooperação e a liberdade de informação podem ser mais propícias à inovação do que a competição e os direitos de propriedade. (CASTELLS, 2003, p. 75).

Ou seja, Castells discutiu esse aspecto antes do surgimento das RSD, num momento em que a internet ainda funcionava de forma menos interativa-comunicacional, os usos eram basicamente de "retirar" da rede aquilo que "alguém da área", em algum lugar havia colocado. 0 que a nova geração da internet possibilitou foi um uso coletivo e aberto: qualquer pessoa com pouco conhecimento de informática pode inserir, criar e retirar conteúdos da rede. Esse uso social sem passar por níveis hierárquicos é que marca um novo momento, que ficou conhecido como a Web 2.0.

Nesse sentido, a contradição pode ser indicada pelo modelo social e econômico vigente, o qual não apresenta nenhum sinal de que busca, defende ou quer uma estrutura horizontalizada, em que nível for. Ao contrário: a estrutura da sociedade atual é altamente verticalizada, com centros de poder não mais focados em pessoas, tal como descrito por Marx na dualidade burgueses-proletários, mas que ainda permanecem encarnados em outros agentes: o mercado, os acionistas, os governos etc. Podemos observar que o modelo econômico, e, por decorrência, o social, adotado nas últimas décadas é de uma estrutura conectada para a realização dos seus negócios e processos por meio das tecnologias de comunicação. A internet em si viabiliza esse modelo econômico, mas não transpõe para o modelo social a estrutura horizontalizada e descentralizada de relações. Contudo, a tecnologia das RSD foi pensada, idealizada e construída para proporcionar relações horizontalizadas, sob a égide de um sistema fortemente alicerçado sobre a verticalidade.

Nesse sentido é que nos pareceu contraditório que a ideia de rede social, enquanto imagem e conceito, pudesse servir como parâmetro para o desenvolvimento de uma tecnologia que possibilita uma experiência contrária ao próprio conceito.

Considerando como hipótese que a criação das redes sociais digitais, assim como provavelmente todos os demais inventos na história humana, tenha sido forjada para suprir uma necessidade objetiva ou subjetiva, quais necessidades subjetivas estavam em jogo naquele momento? 0 que motivou a concepção da rede social digital? Mas, mais importante ainda é entender o que motiva as pessoas a aderirem às redes sociais digitais em escala global. Com base em que conceito, ideia 
ou experiência, a ferramenta foi idealizada (enquanto projeto) e depois concretizada num produto, tal como o Orkut, Facebook etc?

Isso nos levou a buscar compreender essa relação entre pensamento-linguagem-ação. Se a tecnologia foi projetada, se partiu de uma ideia, necessariamente está inserida no campo da linguagem, pois só é possível idealizar algo que seja compreensível pelo pensamento e que, portanto, tenha uma palavra que possa nomear o objeto. Nesse campo, buscamos referência na psicologia, em particular nos estudos de Vygotsky em torno da construção social da linguagem, e na antropologia, com as contribuições de Lévi-Strauss. Duas citações podem nos ajudar nessa discussão:

No principio era a ação. A palavra não foi o princípio - a ação já existia antes dela; a palavra é o final do desenvolvimento, o coroamento da ação. (VYGOTSKY, 1993, p. 131)

[...] dum ponto de vista lógico pode-se compreender por que razão se utilizam imagens tiradas da experiência. Esta é a originalidade do pensamento mitológico - desempenhar o papel do pensamento conceptual. (LÉVI-STRAUSS, 1987, p. 29)

Pela perspectiva de Vygotsky, pudemos compreender que é a experiência que traz os elementos para o pensamento, para a formulação do conceito. Portanto, do ponto de vista da psicologia, o conceito é forjado como resultado da ação interiorizada, compreendida e formalizada pela palavra, a qual, mediante os usos em contextos distintos, constitui significados que passam a ser compartilhados pelos grupos humanos. Disse ainda o autor bielo-russo:

[...] a formação de conceitos é um processo criativo, e não um processo mecânico e passivo; [...] um conceito surge e se configura no curso de uma operação complexa, voltada para a solução de algum problema [...] [tampouco] segue o modelo de uma cadeia associativa [...] trata-se de um processo orientado para um objetivo, uma série de operações que servem de passos em direção a um objetivo final. (VYGOTSKY, 1987, p. 47)

Essas questões nos abriram uma série de questionamentos, pois, se retomarmos as experiências mais arcaicas de formação da linguagem, indagamos qual a base concreta da experiência do sujeito com o meio que permitiu a constituição do conceito de rede. E, depois disso, qual foi a experiência que permitiu vincular o conceito-objeto rede à dimensão do social, associando-o à organização coletiva dos sujeitos? E, por fim, como toda essa experiência em torno do conceito de rede (hierárquica, vinculada à experiência real versus nãohierárquica, mais relacionada à utopia) motivou a idealização e concretização da tecnologia das RSD? Que tendências intrínsecas aos sujeitos mobilizaram-nos no nível do pensamento, primeiro para a criação do conceito, da palavra que nomeava um objeto, e, posteriormente, para transportar esse conceito para nomear um comportamento social? Qual a relação entre rede (reticular, linhas e nós conectados horizontalmente) com relação social (indivíduos isolados, organizados verticalmente)?

$\mathrm{Na}$ imagem, no objeto rede, o que se tem é uma continuidade de linhas que se cruzam e se entrelaçam, passando pelos nós, criando ligações entre eles, e essa dependência entre todas as linhas da rede objetivada pelos nós constitui a própria essência da rede. Não existe rede se não houver linhas fortemente interconectadas. 0 que caracteriza a rede é a absoluta dependência de todos os nós entre si.

0 conceito puro de sociedade ou de indivíduo são abstrações, assim como a ideia de que o indivíduo se resume à sua dimensão biológica, pois, a rigor, o conceito de indivíduo significa muito mais do que seu corpo. Por indivíduo, compreende-se o ser biológico que se diferencia (portanto, se desvincula) dos 
demais quanto aos interesses e pontos de vista, que faz substância de si mesmo e coloca como norma a sua autopreservação e seu próprio desenvolvimento pela construção de uma subjetividade, de um pensamento autônomo (ADORNO; HORKHEIMER, 1973). Está, portanto, na própria essência do indivíduo, a autonomia, a diferenciação e, em alguma medida, a desvinculação. Essa compreensão significa que, ao mesmo tempo em que indivíduo é um ser aprisionado (à sociedade, pois só existe indivíduo se existir sociedade), é liberto (o indivíduo só é indivíduo caso se diferencie do todo na sua individualidade).

Sabemos que a relação do indivíduo com a coletividade na atualidade é marcada por forte competitividade e individualismo, ou seja, ele está inserido na sociedade por meio de relações frágeis (ADORNO; HORKHEIMER, 1986; MARCUSE, 1982; HARVEY, 1994; CROCHIK, 1999). Com isso, parece-nos haver uma contradição em termos de experiência subjetiva entre as relações nas redes sociais digitais e na vida cotidiana. Nos relacionamentos por meio das redes sociais digitais, é possível falar em compartilhamento, em coletividade de iguais; nos demais espaços, não é possível, pois na sociedade predomina a competição e o individualismo. A contradição se expressa, portanto, entre a experiência na sociedade, que é marcada por uma estrutura hierárquica, e aquela vivida nas redes sociais digitais, que é oposta à hierarquia.

Diante dessa questão instigante em torno do conceito, motivamo-nos a mapear os grupos de pesquisadores brasileiros cuja temática sejam as redes sociais. Onde estão esses grupos? A que áreas do conhecimento e instituições estão vinculados? Por quais temas se interessam? Para finalizar este artigo, apresentamos alguns resultados desse levantamento, que teve fundamentalmente a proposta de traçar o perfil de tais grupos.

\section{A pesquisa e os pesquisadores das redes sociais}

0 levantamento de dados foi realizado na base de dados do Diretório de Grupos de Pesquisa do $\mathrm{CNPq}$, com as palavras-chave rede social e rede social digital, no singular e no plural. A coleta ocorreu no primeiro semestre de 2013 e, naquele momento, encontramos 307 grupos de pesquisa, sendo que 284 foram localizados com o termo rede social e 23, com o termo rede social digital.

Para a organização dos dados, criamos um instrumento de pesquisa com os seguintes campos: nome do grupo, descrição, ano de criação, endereço eletrônico, líder, área de conhecimento, curso de graduação ou pósgraduação e instituição a que está vinculado. Os dados foram inseridos numa planilha do Excel e, depois, importados para tratamento no software estatístico Sphinx Léxica V. 5.0.

Em termos de ano de criação, não estabelecemos limite temporal. Encontramos o primeiro grupo com registro de 1982. Sabemos que, nessa época, ainda não existia esse aplicativo do CNPq para registro eletrônico dos grupos de pesquisa. Portanto, consideramos que os líderes tenham colocado essas datas para registrar o início efetivo das pesquisas nas universidades. Os resultados estão na Tabela 1.

Para analisar se a quantidade de grupos ano a ano poderia apresentar um crescimento regular, ou seja, uma elevação esperada, foi utilizado o teste do Qui ${ }^{2}$. 0 resultado nos mostrou que os anos de 2002 (7,1\%), 2006 (7,7\%), 2008 (9\%), 2009 $(9,6 \%)$ e $2010(14,1 \%)$ apresentaram quantidade de grupos que foi considerada acima da quantidade esperada dentro da curva de crescimento em relação aos anos anteriores. Isso nos indicou que o assunto pode, de alguma maneira, ter mobilizado os pesquisadores de forma mais intensa a partir do início do século XXI. 
Tabela 1 - Distribuição de frequência quanto ao ano de criação dos grupos de pesquisa

\begin{tabular}{|c|c|c|}
\hline Ano & Freq. & $\%$ \\
\hline 1982 & 1 & $0,3 \%$ \\
\hline 1983 & 1 & $0,3 \%$ \\
\hline 1985 & 1 & $0,3 \%$ \\
\hline 1986 & 2 & $0,6 \%$ \\
\hline 1988 & 3 & $1,0 \%$ \\
\hline 1989 & 1 & $0,3 \%$ \\
\hline 1990 & 2 & $0,6 \%$ \\
\hline 1991 & 1 & $0,3 \%$ \\
\hline 1992 & 2 & $0,6 \%$ \\
\hline 1993 & 5 & $1,6 \%$ \\
\hline 1994 & 3 & $1,0 \%$ \\
\hline 1995 & 9 & $2,9 \%$ \\
\hline 1996 & 8 & $2,6 \%$ \\
\hline 1997 & 5 & $1,6 \%$ \\
\hline 1998 & 6 & $1,9 \%$ \\
\hline 1999 & 3 & $1,0 \%$ \\
\hline 2000 & 20 & $6,4 \%$ \\
\hline 2001 & 5 & $1,6 \%$ \\
\hline $2002^{*}$ & 22 & $7,1 \%$ \\
\hline 2003 & 11 & $3,5 \%$ \\
\hline 2004 & 21 & $6,7 \%$ \\
\hline 2005 & 12 & $3,9 \%$ \\
\hline 2006 & 24 & $7,7 \%$ \\
\hline 2007 & 12 & $3,9 \%$ \\
\hline 2008 & 28 & $9,0 \%$ \\
\hline 2009 & 30 & $9,6 \%$ \\
\hline 2010 & 44 & $14,1 \%$ \\
\hline 2011 & 20 & $6,4 \%$ \\
\hline 2012 & 10 & $3,2 \%$ \\
\hline TOTAL & 312 & $100 \%$ \\
\hline
\end{tabular}

Fonte: Elaboração dos autores.

${ }^{*} 0$ teste do Qui2 apresentou o resultado de 313,54, com gl = 28, 1-p = $>99,99 \%$ e foi calculado com frequências teóricas iguais para cada categoria. Apresentou valores acima dos esperados nos anos hachurados na tabela.

Procuramos empreender a análise também em termos geográficos, organizando os dados segundo as regiões brasileiras. Vejamos abaixo.

Tabela 2 - Distribuição de frequência quanto à quantidade de grupos de pesquisa por região do Brasil

\begin{tabular}{c|c:c:c:c}
\hline Região & Freq. & $\%$ & Total por região* & $\%$ \\
\hline Norte & 7 & $2,2 \%$ & 1083 & $0,6 \%$ \\
\hline Nordeste & 70 & $22,4 \%$ & 1965 & $3,6 \%$ \\
\hline Centro $^{* *}$ & 26 & $8,3 \%$ & 5858 & $0,4 \%$ \\
\hline Sudeste $^{\star *}$ & 138 & $44,2 \%$ & 12.877 & $1,1 \%$ \\
\hline Sul & 71 & $22,8 \%$ & 6204 & $1,1 \%$ \\
\hline TOTAL & 312 & $100 \%$ & 27.987 & $1,1 \%$ \\
\hline
\end{tabular}

Fonte: Elaboração dos autores.

*Total de Grupos de Pesquisa segundo o censo de 2010. Fonte:<www.cnpq.br>. ** 0 teste do Qui2 apresentou o resultado de 164,12, com gl $=4,1-p=>99,99 \%$. 0 Qui2 é calculado com frequências teóricas iguais para cada categoria. Apresentou valores acima dos esperados nos anos hachurados na tabela.
Em termos regionais, a região sudeste $(44,2 \%)$ foi a que apresentou uma quantidade relativamente superior às demais, mostrando que a distribuição pelas regiões não é equilibrada. Contudo, numa análise em termos de proporcionalidade da quantidade de grupos de pesquisa sobre redes sociais em cada região e o total de grupos de pesquisa da mesma região, o nordeste é a que apresenta uma quantidade proporcional maior de grupos de pesquisa sobre redes sociais $(3,6 \%)$ em relação ao total de grupos de pesquisa da região. Nas demais regiões, as proporções mantêm-se em torno de $1 \%$, como pode ser observado na tabela 2 .

Em relação às instituições, não foi possível mostrar os dados na forma de tabela devido à sua extensão; por isso, optamos por fornecer apenas os mais relevantes. Quanto à distribuição pelas IES, apresentaram quantidade de grupos acima do esperado a USP (5,8\%), UFRGS (4,2\%), FIOCRUZ (3,9\%), UFRJ (3,9\%), UNB (3,9\%) e UFBA (2,9\%). Dentre essas, somente a FIOCRUZ e a UFRJ possuem grupos de pesquisa sobre redes sociais vinculados à área das ciências da saúde. Nas demais, os grupos estão em duas áreas: ciências sociais aplicadas e ciências humanas, às quais estão vinculados, respectivamente, os cursos de comunicação e educação.

Em termos de vinculação à área do conhecimento, na tabela 3, apresentamos os resultados da distribuição.

Tabela 3 - Distribuição de frequência dos grupos de pesquisa pelas áreas do conhecimento

\begin{tabular}{c|c:c}
\hline Área & Freq. & $\%$ \\
\hline Ciências sociais aplicadas* $^{*}$ & 124 & $39,7 \%$ \\
\hline Ciências humanas & 104 & $33,3 \%$ \\
\hline Ciências da saúde & 37 & $11,9 \%$ \\
\hline Engenharias e C. computação & 32 & $10,3 \%$ \\
\hline Ciências exatas e da terra & 8 & $2,6 \%$ \\
\hline Linguística, letras e artes & 5 & $1,6 \%$ \\
\hline Ciências agrárias & 2 & $0,6 \%$ \\
\hline TOTAL CIT. & 312 & $100 \%$ \\
\hline
\end{tabular}

Fonte: Elaboração dos autores.

* 0 teste do Qui2 apresentou o resultado de 409,64, com gl =7,1-p =>99,99\%. 0 Qui2 é calculado com frequências teóricas iguais para cada categoria. Apresentou valores acima dos esperados nos anos hachurados na tabela. 
Nessas áreas, os cursos de comunicação e educação são os que mais possuem grupos de pesquisa vinculados, pois apresentaram valores acima do esperado, em função dos resultados encontrados com o teste estatístico aplicado. E, para finalizar os dados de perfil desses grupos, realizamos tratamento analítico e estatístico para compreender suas temáticas de maior interesse. Para tanto, fizemos inicialmente um trabalho de categorização sobre a variável em que foram inseridos na íntegra os textos de descrição do grupo e das linhas de pesquisa registrados na base de dados do CNPq, que devem refletir o escopo de atuação do grupo. Cabe ainda observar que a quantidade de citações é superior à quantidade de grupos de pesquisa, pois essa variável era de múltipla escolha, já que, em geral, os grupos tratavam de mais de um tema. 0 resultado encontra-se na Tabela 4.

Tabela 4 - Distribuição de frequência quanto aos temas de pesquisa dos grupos de pesquisa

\begin{tabular}{|c|c|c|}
\hline Temas de Pesquisa & Freq. & $\%$ \\
\hline Questões econômicas e sociais* & 74 & $9,7 \%$ \\
\hline Transformações sociais e culturais & 69 & $9,0 \%$ \\
\hline Colaboração, processos em rede & 59 & $7,7 \%$ \\
\hline Estudos de organizações & 59 & $7,7 \%$ \\
\hline Políticas públicas & 58 & $7,6 \%$ \\
\hline Tecnologia digital e comunicação & 57 & $7,5 \%$ \\
\hline Redes sociais, estrutura das & 52 & $6,8 \%$ \\
\hline Informação e conhecimento & 50 & $6,6 \%$ \\
\hline Saúde e inovação tecnológica & 49 & $6,4 \%$ \\
\hline Educação e tecnologia & 48 & $6,3 \%$ \\
\hline Questões urbanas & 31 & $4,1 \%$ \\
\hline Desenvolvimento de tecnologia & 30 & $3,9 \%$ \\
\hline Subjetividade e tecnologia digital & 20 & $2,6 \%$ \\
\hline Formação profissional & 19 & $2,5 \%$ \\
\hline Inclusão & 17 & $2,2 \%$ \\
\hline Cibercultura & 12 & $1,6 \%$ \\
\hline Questões rurais & 11 & $1,4 \%$ \\
\hline Processos democráticos & 10 & $1,3 \%$ \\
\hline Estudos ecológicos e biológicos & 7 & $0,9 \%$ \\
\hline Pessoas com deficiência & 4 & $0,5 \%$ \\
\hline Total cit. & 763 & $100 \%$ \\
\hline \multicolumn{3}{|c|}{$\begin{array}{l}\text { Fonte: Elaboração dos autores. } \\
\text { * } 0 \text { teste do Qui2 } 2 \text { apresentou o resultado de } 277,12, \text { com gl }=21,1-p= \\
>99,99 \% \text {. } 0 \text { Qui2 é calculado com frequências teóricas iguais para cada } \\
\text { categoria e foi construído sobre } 312 \text { observações. Os percentuais são } \\
\text { calculados em relação ao número de citações. Apresentou valores acima } \\
\text { dos esperados nos anos hachurados na tabela. }\end{array}$} \\
\hline
\end{tabular}

Conforme podemos observar na tabela 4, as categorias analíticas "Questões econômicas e sociais" (9,7\%) e "Transformações sociais e culturais" (9\%) foram as que apresentaram uma quantidade de citações acima do esperado, ou seja, esses assuntos surgem entre os grupos de pesquisa numa incidência maior em relação aos demais. Se confrontamos esse resultado com os dados anteriores em relação às áreas do conhecimento com maior número de grupos de pesquisa (comunicação e educação), podemos inferir que os grupos de pesquisa que têm como tema as redes sociais e estão vinculados a essas áreas preocupam-se com os processos sociais ligados às dimensões econômicas e culturais. Esse aspecto denota um perfil da pesquisa brasileira sobre o tema das redes sociais com forte comprometimento social, pois também identificamos que os autores mais citados são da sociologia e filosofia: Manuel Castells e Pierre Lévy.

Essa característica nos indica que a produção brasileira sobre redes sociais está sendo construída alicerçada em bases sociológica e humanística, e menos sobre uma base tecnológica ou comportamental, que é uma das características da produção científica estadunidense sobre redes sociais.

\section{Considerações sobre a pesquisa}

Numa pesquisa, sabemos por onde começar, mas nem sempre onde terminar. A investigação que nos propusemos a realizar inicialmente se restringia a analisar a produção bibliográfica brasileira sobre o tema das redes sociais digitais e identificar potencialidades para seu uso em ações de promoção da saúde.

Esse percurso trouxe à tona questões de fundo, de cunho filosófico e sociológico, que nos desafiavam a adentrar ainda mais o assunto. Finalizamos a pesquisa em julho de 2013 com a certeza de que desnudamos unicamente algumas faces da problemática das RSD e do contexto social.

A sociedade, enquanto constructo conceitual, só foi possivel quando o ser biológico 
se desvinculou da natureza e constituiu-se como um ser cultural. Cada um é uma linha que tece sua história. Por isso, podemos falar de "linha da vida", "linha do tempo". A linha tem direção e sentido dualizado (cima, baixo; esquerda, direita), tem duas pontas, pode representar passado e futuro. Rede, por seu turno, espraia-se para os quatro lados. Suas linhas se interligam em mil nós como vínculos indissolúveis. Isso constitui uma rede. Se os nós forem desfeitos, a rede deixa de existir, torna-se um emaranhado de linhas. Sua essência são suas ligações.
Nesse sentido, muito mais que uma tecnologia da moda, as RSD podem estar respondendo a anseios humanos e podem ser elementos de tensão na sociedade atual. Manifestações organizadas pela rede são noticiadas com frequência, mostrando o potencial de mobilização social. A U-topia de Thomas Morus, do "lugar que não existe", parece-nos em muito com o fenômeno das redes sociais digitais: ele existe, mas não podemos apanhá-lo. Mas essas são questões ainda em aberto, desafiando-nos permanentemente.

\section{Referências}

ADORNO, Theodor W.; HORKHEIMER, Max. Dialética do esclarecimento: fragmentos filosóficos. 2. ed. Tradução Guido Antonio de Almeida. Rio de Janeiro: Jorge Zahar, 1986.

BRANDÃO, Junito de Souza. Mitologia grega. v. 1. Petrópolis: Vozes, 1986.

CASTELLS, Manoel. A Galáxia da internet: reflexões sobre a internet, os negócios e a sociedade. Rio de Janeiro: Zahar, 2003.

CASTELLS, Manoel. A sociedade em rede: a era da informação: economia, sociedade e cultura. v. 1. São Paulo: Paz e Terra, 1999.

CROCHIK, José Leon. A ideologia da racionalidade tecnológica e a personalidade narcisista. Tese (Livre-docência) - Instituto de Psicologia da Universidade de São Paulo. São Paulo: IPUSP, 1999.

HARVEY, David. A condição pós-moderna: uma pesquisa sobre as origens da mudança cultural. 4. ed. São Paulo: Loyola, 1994. HORKHEIMER, Max; ADORNO, Theodor W. Temas básicos da sociologia. São Paulo: Cultrix: Edusp, 1973.

JUNG, Carl G. et al. 0 homem e seus símbolos. Rio de Janeiro: Nova Fronteira, 2002.

LÉVI-STRAUSS, Claude. Mito e significado. Lisboa: Edições 70, 1987.

MARCUSE, Herbert. El final de la utopía. Barcelona: Planeta Agostini, 1968.

MARCUSE, Herbert. Eros e civilização: uma interpretação filosófica do pensamento de Freud. Rio de Janeiro: Zahar, 1982.

MARCUSE, Herbert. Ideologia da sociedade industrial. 3. ed. Tradução Giosone Rebuá. Rio de Janeiro: Zahar, 1969.

MARX, Karl. Manuscritos econômicos e filosóficos. São Paulo: Martin Claret, 2001. (A obra-prima de cada autor).

MARX, Karl. Miséria da filosofia. São Paulo: Martin Claret, 2008. (A obra-prima de cada autor).

MARX, Karl. 0 capital: crítica da economia política. v. 1, livro primeiro. 2. ed. São Paulo: Nova Cultural, 1985.

MORUS, Thomas. Utopia. Disponível em: <http://www.ebooksbrasil.org/eLibris/utopia.html>. Acesso em: 23 jul. 2012.

PARROCHIA, Daniel. Quelques aspects historiques de la notion de réseau. In: Flux, n. 62, p. 10-20, out./dez. 2005. Disponível em: <http://olegk.free.fr/flux/Flux62/pdffl62/02Parrochia10-20.pdf>. Acesso em: 03 maio 2013. 
PORTUGAL, Silvia. Contributos para uma discussão do conceito de rede na teoria sociológica. Disponível em: <http://www. ces.uc.pt/publicacoes/oficina/271/271.pdf>. Acesso em: 21 jul. 2012.

SANTOS, Milton. A natureza do espaço: técnica e tempo, razão e emoção. 3. ed. São Paulo: Hucitec, 1999.

VYGOTSKY, Lev S. Pensamento e linguagem. São Paulo: Martins Fontes, 1987.

Recebido em: 17.09.2013

Aprovado em: 17.03.2014

Sônia Cristina Vermelho é doutora em Educação: história, política, sociedade (Educação e Ciências Sociais) pela Pontifícia Universidade Católica de São Paulo, pós-doutora pela Universidade do Porto/INESC-Porto (2013). Atualmente é professora e pesquisadora do Núcleo de Tecnologia Educacional para Saúde (NUTES), do Centro de Ciências da Saúde da Universidade Federal do Rio de Janeiro.

Ana Paula Machado Velho é doutora em Comunicação e Semiótica pela Pontifícia Universidade Católica de São Paulo, pós-doutoranda junto ao Laboratório de Arte e Tecnologia (LArt) da Universidade de Brasília (UnB), professora dos programas de pós-graduação em Promoção da Saúde e de Tecnologias Limpas da UniCesumar, e professora do curso de jornalismo da UniCesumar.

Valdecir Bertoncello é mestre em Tecnologias em Saúde pela Pontifícia Universidade Católica do Paraná, doutorando em Engenharia de Produção pela Universidade Federal de Santa Catarina, diretor do Centro de Ciências Exatas, Tecnológicas e Agrárias do Centro Universitário de Maringá - UniCesumar. 
